\title{
EVALUATION OF SERUM NITRIC OXIDE IN ESSENTIAL HYPERTENSION AND ITS CORRELATION WITH SEVERITY OF DISEASE
}

\author{
SARTHAK RANJAN NAYAK ${ }^{1 *}$, ITISHRI JENA ${ }^{1}$, PRAMILA KUMARI MISHRA², SUDESHNA BEHERA ${ }^{1}$, \\ SUBHASHREE RAY ${ }^{1}$
}

${ }^{1}$ Department of Biochemistry, IMS and SUM Hopspital, Siksha 'O' Anusandhan University, Bhubaneswar, Odisha, India. 'Department of Biochemistry, MKCG Medical College, Berhampur University, Brahmapur, Odisha, India. Email: drsarthak.nayak@gmail.com

\author{
Received: 14 June 2016, Revised and Accepted: 16 June 2016
}

\section{ABSTRACT}

Objective: Hypertension is the most common cardiovascular disease and one of the most important public health concerns all over the world. Primary or essential hypertension is the major form of arterial hypertension without any definitive cause. It results from increase vascular tone and resistance which may be confined to the lower level of endothelial derived relaxing factor such as nitric oxide (NO). Hence, the objective of this study is to find out whether any correlation exists between the concentrations of serum NO (nitrite) and essential hypertensive patients categorized according to the Joint National Committee 7 classification.

Methods: We selected age- and sex-matched 24 healthy individuals as controls and 35 essential hypertensive patients as cases. Out of 35 cases, 24 were included in stage 1 and 11 in stage 2 of essential hypertension. We estimated serum NO levels in study groups basing on the principle of Griess reaction.

Results: We observed reduction in mean serum NO level in cases which was statistically highly significant as compared to controls (8.14 \pm 0.33 vs. $13.53 \pm 0.38 \mu \mathrm{mol} / \mathrm{L}, \mathrm{p}<0.001)$ and also in stage 2 patients when compared with stage 1 patients $(5.97 \pm 0.31$ vs. $9.15 \pm 0.28 \mu \mathrm{mol} / \mathrm{L}$, p<0.001). In hypertensive patients, serum NO showed a highly significant inverse correlation to both systolic $(\mathrm{r}=-0.89, \mathrm{p}<0.001)$ as well as diastolic $(\mathrm{r}=-0.64$, $\mathrm{p}<0.001$ ) blood pressure.

Conclusion: Thus, we can conclude that lower level of serum NO can be an important causative factor in the progress of essential hypertension.

Keywords: Essential hypertension, Endothelial-derived relaxing factor, Nitric oxide, Joint National Committee 7

(c) 2016 The Authors. Published by Innovare Academic Sciences Pvt Ltd. This is an open access article under the CC BY license (http://creativecommons. org/licenses/by/4. 0/) DOI: http://dx.doi.org/10.22159/ajpcr.2016.v9s2.13464

\section{INTRODUCTION}

Hypertension is the most common, asymptomatic, readily detectable, usually easily treatable disorder, and if untreated it often leads to complications like coronary heart disease, stroke, and other vascular complications. It has been estimated that hypertension accounts for 7.5 million deaths, which is about $12.8 \%$ of annual deaths worldwide. Around the world, the prevalence of hypertension in person belonging to the age group of 25 or more is almost $40 \%$, rise of prevalence from 600 million in 1980 to approximately 1 billion in 2008. According to the WHO, the prevalence of hypertension among the males is slightly higher than the females [1].

Development of hypertension is considered to be multifactorial. Both environmental and genetic factors may contribute to regional and racial variations of blood pressure (BP) and hypertension prevalence. Obesity and weight gain are found to be strong and independent risk factors. Other risk factors such as low dietary intakes of calcium, potassium, alcohol consumption, psychosocial stress, and low levels of physical activity are also contributing to the increasing prevalence. The studies show a significant heritable component to BP levels and hypertension. It has been well-documented that before the age of 50 years, the prevalence of hypertension appears to be somewhat lower in women than in men, suggested by protective roles of estrogen in women. However, after menopause, the occurrence of hypertension increases rapidly in women and exceeds that in men [2].

Hypertension is typically a disorder of circulatory regulation. Current clinical criteria which ideally define hypertension are generally based on the average of two or more seated BP readings during each of two or more outpatient visits. Classification proposed by the Joint National Committee 7 (JNC 7), defines a BP of $<140 / 90 \mathrm{~mm} \mathrm{Hg}$ as acceptable, rise of $\mathrm{BP}$ beyond this is considered as hypertension. $\mathrm{BP}<120 / 80 \mathrm{~mm} \mathrm{Hg}$ is normal. Systolic BP (SBP) 140-159 mm Hg or diastolic BP (DBP) 90-99 $\mathrm{mm} \mathrm{Hg}$ are included in stage 1 and SBP $\geq 160 \mathrm{~mm} \mathrm{Hg}$ or DBP $\geq 100 \mathrm{~mm}$ Hg in stage 2 hypertensions [3].

Essential, primary or idiopathic hypertension is defined as high BP without any definable cause in which various secondary causes such as renovascular disease, renal failure, pheochromocytoma, aldosteronism or other causes of secondary hypertension, or mendelian forms (monogenic) are not present. This the most prevalent form of hypertension accounting for approximately $80-95 \%$ of all hypertensive patients. Remaining 5-15\% specific underlying cause has been identified $[2,4]$. Essential hypertension usually associated with other cardiovascular risk factors such as aging, abdominal obesity, dyslipidemia, glucose intolerance, insulin resistance, diabetes, and hyperuricemia [4]. In developed as well as in developing countries essential hypertension affects $25-35 \%$ of the adult population and up to $60-70 \%$ of those beyond the seventh decades of life [5]. Essential hypertension suggested to be a familial disease and likely to be an interaction between environment and genetic factors. It is mostly characterized by endothelial dysfunction and increase vascular tone and resistance due to mismatch between endothelial-derived relaxing factor (EDRF) and contracting factors [6].

Nitric oxide (NO) is synthesized from L-arginine by the enzyme NO synthase (NOS) which exists as three different isoforms: Neuronal NOS, inducible NOS, and endothelial NOS (eNOS). Platelets express eNOS and in endothelial cells, it catalyzes the formation of NO and L-citrulline from L-arginine, with the aid of tetrahydrobiopterin (BH4), molecular oxygen, and nicotinamide adenine dinucleotide phosphate cofactors. NO is now found to be the major form of EDRF. eNOS is 
activated by various sterssors in response to increase accumulation of intracellular calcium and thus triggering the increase production and extracellular release of NO. NO plays a catalytic role in conversion of guanosine triphosphate to cyclic guanosine monophosphate (cGMP) by activating soluble guanylate cyclase. The elevated cGMP regulates many vital physiological functions leading to relaxation of vascular smooth muscles [7]. Vasodilatation inhibits platelet and leukocyte adhesion to the endothelium and inhibits vascular smooth muscle cell proliferation. Reduction in basal NO release may prejudice humans to hypertension, thrombosis, vasospasm and atherosclerosis and restoration of NO activity can induce regression of pre-existing intimal lesions [8] NO is effective only for few seconds. Its stable oxidative end product nitrite and nitrate diffuse into the circulation and finally excreted in urine [9]. Reduced level of NO synthesis and release may be resulted from decreased NOS expression [10], elevated level of endothelial NOS competitive inhibitor like asymmetric dimethyl arginine [11] or accelerated break down of NO by the enhanced formation of reactive oxygen species, mostly the superoxide anion [12]

Hypertension is a global health concern and related to altered vascular tone. However, a very few studies have been done to investigate the correlation between the NO and essential hypertension. Considering the above facts, the present research was carried to assess the status of serum NO in essential hypertension and whether any coexisting correlation with severity of the disease.

\section{METHODS}

This study was undertaken in the Department of Biochemistry, V.S.S Medical College and Hospital, Burla. Patients were collected from in and outpatient Departments of Medicine and Cardiology. Those patients taking antihypertensive drugs or having drug- induced or drug-related hypertension, chronic kidney disease, primary hyperaldosteronism, renovascular disease, chronic steroid therapy and Cushing's syndrome, pheochromocytoma, coarctation of aorta, thyroid and parathyroid disease, and sleep apnea were excluded from our study. A total of 35 essential hypertensive patients between 25 and 55 years of age were included as cases, again categorized into stage $1(n=24)$ and stage 2 $(n=11)$ according to the JNC 7. 24 age- and sex-matched apparently healthy individuals were taken as controls. The purpose and procedure of the study were explained to the study groups and has been approved by the Institutional Ethical Committee.

$5 \mathrm{ml}$ venous samples were collected from study groups, and serum was separated and analyzed for serum NO, urea, creatinine, and electrolytes such as sodium, potassium, and ionized calcium. Serum urea and creatinine were estimated using fully automated analyzer Cobas Integra 400 plus. Serum sodium, potassium, and ionized calcium were analyzed in electrolyte analyzer instrument (ECOLYTE of ESCHWEILER).

Serum NO estimated by Griess reaction. Griess reaction is based on the principle that, in an oxygenated solution, NO decomposes to form nitrite $\left(\mathrm{NO}_{2}^{-}\right)$and nitrate $\left(\mathrm{NO}_{3}^{-}\right)$. The only stable product formed by spontaneous auto-oxidation of NO in oxygenated solutions is nitrite $\left(\mathrm{NO}_{2}{ }^{-}\right)$. Nitrite reacts with sulfanilamide and heterocyclic amine of naphthylene-ethylene-diamine (Griess reagent) under conditions of low $\mathrm{pH}$ to form a magenta colored azo dye that can be measured in the spectrophotometer at $540 \mathrm{~nm}$ [13].

Statistical analysis was done with Chi-square test and independent t-test. All the analyses were done using statistical software SPSS 20.0 . The associations were considered statistically significant if the $\mathrm{p}<0.05$.

\section{RESULTS}

This study enrolled 35 essential hypertensive patients as cases, out of which 24 were categorised into stage 1 and 11 into stage 2 according to JNC 7 classification. A total of 24 numbers of age- and sex-matched apparently healthy individuals were taken as control. Out of the 24 healthy controls, 13 (54\%) were male, and 11 (46\%) were female.
About $37 \%$ of healthy controls are in $25-39$ years of age groups, and $63 \%$ are in the $40-55$ years of age group. About $69 \%$ of the hypertensive patients are in the $40-55$ year age group whereas only $31 \%$ of cases are in the lower age group of 25-39 year. In the patients group, a total number of the male (51.4\%) and female (48.6\%) are almost equivalent. The mean age for healthy controls group was $38.33 \pm 1.62$ with range of $26-53$ years and for hypertensive patients was $43.46 \pm 1.53$ with range of 27-54 years.

Table 1 showed the study of family history among the study groups. Applying Chi-square test, it was found that family history of hypertension is positively correlated $(0.032)$ to the development of essential hypertension which is statistically significant $(\mathrm{p}<0.05)$.

Table 2 shows the comparison of body mass index (BMI), systolic, and DBP among the healthy controls and hypertensive patients. Comparison of BMI between the hypertensive patients and healthy control shows no statistically significant ( $p>0.05$ ) difference, but a highly significant rise $(p<0.001)$ in both systolic and DBP was found in hypertensive as compared to control.

Table 3 shows the comparison of serum urea, creatinine, serum NO, and electrolytes such as sodium, potassium, and ionized calcium among the healthy and hypertensive patients. It was found that significant difference of serum creatinine $(\mathrm{p}<0.05)$ and ionized calcium $(\mathrm{p}<0.001)$ among the study groups but other parameters show no statistical difference $(p>0.05)$. We found a highly significant reduction $(p<0.001)$ of serum NO (nitrite) level in essential hypertensive patients when compared to healthy control group.

Table 4 shows the comparison of serum NO between stages 1 and 2 hypertensive patients. Serum NO was lower in stage 2 hypertensive

Table 1: Family history of hypertension in the study groups

\begin{tabular}{lllll}
\hline F/H & Controls $(\mathbf{n = 2 4 )}$ & Cases $(\mathbf{n}=\mathbf{3 5})$ & Total & p value \\
\hline Positive & $9(38 \%)$ & $23(66 \%)$ & 32 & $<0.05^{*}$ \\
Negative & $15(62 \%)$ & $12(34 \%)$ & 27 & \\
\hline
\end{tabular}

${ }^{*} \mathrm{p}<0.05$ is considered to be significant

Table 2: Study of BMI, SBP and DBP among the controls and hypertensive patients

\begin{tabular}{llll}
\hline Parameters & \multicolumn{2}{l}{ Mean \pm SEM } & \multirow{2}{*}{ p value } \\
\cline { 2 - 3 } & Controls (n=24) & Cases $(\mathbf{n = 3 5 )}$ & \\
\hline BMI $\left(\mathrm{Kg} / \mathrm{m}^{2}\right)$ & $24.57 \pm 0.03$ & $25.5 \pm 0.43$ & $\mathrm{NS}$ \\
SBP $(\mathrm{mm} \mathrm{Hg})$ & $121.0 \pm 1.77$ & $154.0 \pm 2.9$ & $<0.001^{* *}$ \\
DBP (mm Hg) & $76.3 \pm 1.24$ & $93.3 \pm 1.33$ & $<0.001^{* *}$ \\
\hline
\end{tabular}

${ }^{*} \mathrm{p}<0.05$ (significant), ${ }^{* *} \mathrm{p}<0.001$ (highly significant). BMI: Body mass index, SBP: Systolic blood pressure, DBP: Diastolic blood pressure, SEM: Standard error of the mean, NS: Not significant

Table 3: Study of serum urea, creatinine, electrolytes, and NO among the study groups

\begin{tabular}{|c|c|c|c|}
\hline \multirow[t]{2}{*}{ Parameters } & \multicolumn{2}{|l|}{ Mean $\pm S E M$} & \multirow[t]{2}{*}{ p value } \\
\hline & $\begin{array}{l}\text { Controls } \\
(n=24)\end{array}$ & $\begin{array}{l}\text { Cases] } \\
(n=35)\end{array}$ & \\
\hline Serum urea (mg/dl) & $27.29 \pm 1.45$ & $30.9 \pm 1.23$ & NS \\
\hline Serum creatinine (mg/dl) & $0.85 \pm 0.05$ & $1.08 \pm 0.06$ & $<0.05^{*}$ \\
\hline Serum $\mathrm{Na}^{+}(\mathrm{mEq} / \mathrm{L})$ & $139.66 \pm 0.57$ & $140.1 \pm 0.58$ & NS \\
\hline Serum $\mathrm{K}^{+}(\mathrm{mEq} / \mathrm{L})$ & $4.1 \pm 0.09$ & $3.92 \pm 0.05$ & NS \\
\hline Serum ionized $\mathrm{Ca}^{2+}(\mathrm{mg} / \mathrm{dl})$ & $4.99 \pm 0.35$ & $4.53 \pm 0.39$ & $<0.001^{* *}$ \\
\hline $\mathrm{NO}(\mu \mathrm{mol} / \mathrm{L})$ & $13.53 \pm 0.38$ & $8.14 \pm 0.33$ & $<0.001^{* *}$ \\
\hline
\end{tabular}

${ }^{*} \mathrm{p}<0.05$ (significant), ${ }^{* *} \mathrm{p}<0.001$ (highly significant). NO: Nitric oxide, NS: Not significant, SEM: Standard error of the mean 
patients as compared to the stage 1 patients which were statistically significant $(\mathrm{p}<0.001)$.

Correlations between serum NO and BPs were shown in Figs. 1 and 2. Serum NO when correlated with BP of hypertensive patients, it shows a negative as well as statistically highly significant correlation to both systolic $(\mathrm{r}=-0.89, \mathrm{p}<0.001)$ and diastolic $(\mathrm{r}=-0.64, \mathrm{p}<0.001)$ BP as shown in Figs. 1 and 2, respectively.

\section{DISCUSSION}

NO is well known to be a potent endogenous vasodilator and inhibition of NO synthesis may be associated with rise in BP. Few studies have shown that NO levels are diminished in essential hypertension, and therapeutic control of BP leads to restoration of NO level in these patients. In this study, most of the hypertensive patients (69\%) fall in the age group of 40-55 years. The family history of hypertension

Table 4: Comparison of NO between stage 1 and stage 2 hypertensive patients

\begin{tabular}{llll}
\hline Parameters & \multicolumn{2}{l}{ Mean \pm SEM } & p value \\
\cline { 2 - 3 } & $\begin{array}{l}\text { Stage 1 } \\
\text { hypertension } \\
(\mathbf{n}=\mathbf{2 4 )}\end{array}$ & $\begin{array}{l}\text { Stage 2 } \\
\text { hypertension } \\
(\mathbf{n = 1 1 )}\end{array}$ & \\
\hline NO $(\mu \mathrm{mol} / \mathrm{L})$ & $9.15 \pm 0.28$ & $5.97 \pm 0.31$ & $<0.001^{* *}$ \\
\hline $\begin{array}{l}* * \mathrm{p}<0.001(\text { highly significant). NO: Nitric oxide, SEM: Standard error of the } \\
\text { mean }\end{array}$ & &
\end{tabular}

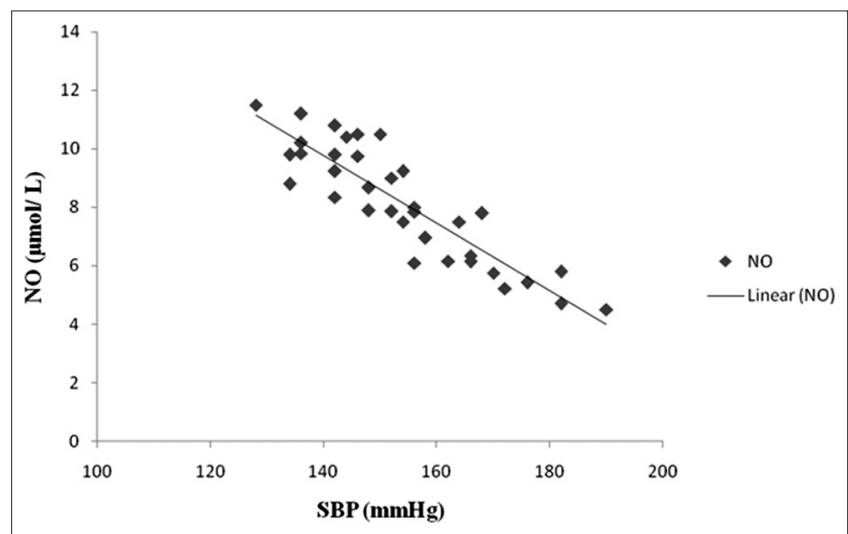

Fig. 1: Correlation between serum nitric oxide and systolic blood pressure in hypertensive patients $(r=-0.89, p<0.001)$

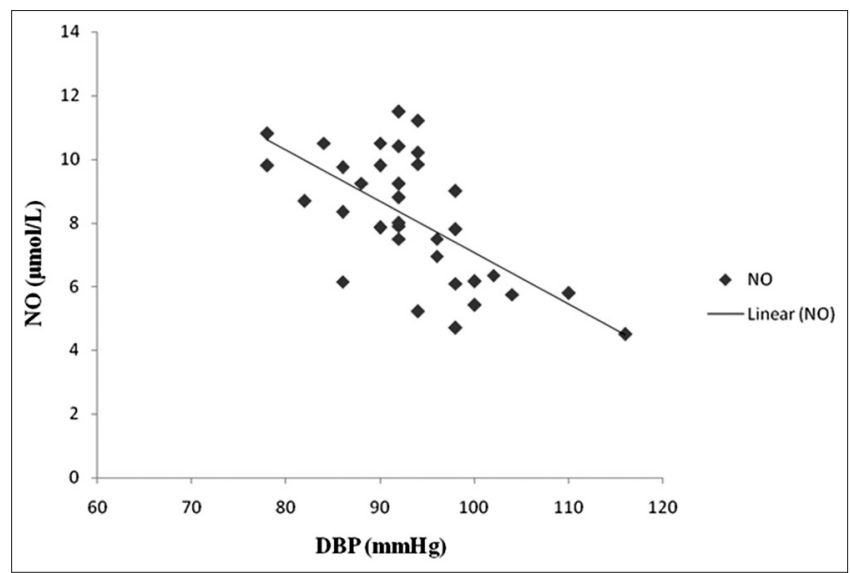

Fig. 2: Correlation between serum nitric oxide and diastolic blood pressure in hypertensive patients $(\mathrm{r}=-0.64, \mathrm{p}<0.001)$ was found in $66 \%$ patients but only in $38 \%$ of healthy control group which was found to be significantly correlated to the development of essential hypertension $(\mathrm{p}<0.05)$. The onset of hypertension is usually between ages 25 and 55 years. The prevalence increases with age and is uncommon before the age of 20 years. A family history of high BP raises the risk of both hypertension and cardiovascular disease [14]

Serum creatinine level found to be raised significantly $(\mathrm{p}<0.05)$ in hypertensive patients compared to healthy control. Serum NO was negatively correlated to serum creatinine of hypertensive patients which is not statistically significant $(\mathrm{r}=-0.276, \mathrm{p}=0.108)$. This study excluded chronic renal complications, and the raised level of creatinine may be attributed to mild renal insufficiency. The study of Ruilope [15] established that mild renal insufficiency is present in significant proportion of hypertensive population. Decreased NO level is a reason behind elevating the BP by alternation of vasodilator properties of vessels wall as well as by impairment of renal hemodynamic and excretory function [16].

Serum electrolyte analysis showed rise in both sodium and potassium level in hypertensive patients compared to control group which is not statistically significant. A highly significant reduction $(p<0.001)$ of serum ionized calcium was detected in hypertensive group when compared to controls. Higher sodium level may be resulted from altered activity of the $\mathrm{Na}^{+} / \mathrm{H}^{+}$antiporter and the $\mathrm{Na}^{+} / \mathrm{Li}^{+}$counter-transporters [17]. High salt intake definitely increases the risk of hypertension [4]. Low potassium intake is a risk factor for the development of hypertension [18] Increased $\mathrm{K}^{+}$intake is well known to have effect on $\mathrm{BP}$ control through various mechanisms, and hypokalemia will blunt reductions in BP by antihypertensive medication perhaps because its result is closure of $\mathrm{K}^{+}$ channels [19]. Our study matches with Levine et al. [20] study about the association between BP level and serum sodium and potassium. They showed no significant association was found between the height of BP, the serum sodium, or potassium level. Similarly, the study of Hvarfner et al. [21] established that plasma ionized calcium was inversely related, and the urinary calcium was positively related to BP in the essential hypertension and healthy control group. The essential hypertensive patient has significantly lower plasma level of ionized calcium $(p=0.02)$ than the control.

In this study, we observed a highly significant diminution of serum NO in both hypertensive versus healthy control group and also in stage 2 against stage 1 patients $(\mathrm{p}<0.001)$. Serum NO showed a highly significant negative correlation with both SBP $(r=-0.89, \mathrm{p}<0.001)$ and DBP $(r=-0.64$, $\mathrm{p}<0.001)$. Numerous studies indicate that NO is the major physiological regulator of basal blood vessel tone. These include the vasoconstrictive action of NOS inhibitors which is accompanied by substantial increase in BP [22]. Our study was well supported by the study of Node et al., [23] who established the end product of NO (nitrate plus nitrite) was reduced in individuals with essential hypertension relative to that in control subjects $(15.7 \pm 1.1$ vs. $22.8 \pm 1.4 \mu \mathrm{mol} / \mathrm{L}, \mathrm{p}<0.001)$. They also found a significant inverse correlation of plasma NO with the SBP ( $r=-0.68$, $\mathrm{p}<0.005)$ and DBP $(\mathrm{r}=-0.61, \mathrm{p}<0.05)$, which is in agreement with our study. Similar studies done by Arora et al. [24] and Chandra et al. [25] observed that a highly significant reduction $(p<0.001)$ in plasma level of NO in essential hypertension patients compare to control group.

\section{CONCLUSION}

Plasma NO level found to be significantly lower in essential hypertensive patients compared to healthy controls and was inversely correlated to both systolic and DBP of patients which was statistically significant. The lower level of $\mathrm{NO}$ in hypertensive patients suggests that the estimation of NO, a simple, and economic method may be included as a routine laboratory investigation for screening people at risk so that therapeutic intervention can be implemented in individuals. Hence, if this work is further supported by more studies it may help in the understanding of NO role in regulating the $\mathrm{BP}$ and its use in appropriate medical intervention in the early phase of disease. However, the reference value for NO is yet to be established in Indian population. 


\section{REFERENCES}

1. Park K. Hypertension. In: Park's Textbook of Preventive and Socia Medicine. 23 $3^{\text {th }}$ ed. Jabalpur, (India): Banarsidas Bhanot Publishers; 2015. p. 372-7.

2. Kotchen TA. Hypertensive vascular disease. In: Kasper DL, Fauci AS, Braunwald E, Hauser SL, Longo DL, Jameson JL, Loscalzo J, editors. Harrison's Principle of Internal Medicine. 19 $9^{\text {th }}$ ed., Vol. II. New York, NY: Mc Graw Hill Companies; 2015. p. 1611-26.

3. Chobanian AV, Bakris GL, Black HR, Cushman WC, Green LA, Izzo JL Jr, et al. Seventh report of the Joint National Committee on prevention, detection, evaluation, and treatment of high blood pressure. Hypertension 2003;42:1206-52.

4. Victor RG. Arterial hypertension. In: Goldman L, Schafer AI, editors Goldman-Cecil Medicine. $25^{\text {th }}$ ed. Philadelphia, PA: Elsvier Publication; 2016. p. 381-96.

5. Carretero OA, Oparil S. Essential hypertension. Part I: Definition and etiology. Circulation 2000;101(3):329-35.

6. Staessen JA, Wang J, Bianchi G, Birkenhäger WH. Essential hypertension. Lancet 2003;361(9369):1629-41.

7. Leiper J, Nandi M. The therapeutic potential of targeting endogenous inhibitors of nitric oxide synthesis. Nat Rev Drug Discov 2011;10(4):277-91.

8. Candipan RC, Wang BY, Buitrago R, Tsao PS, Cooke JP. Regression or progression. Dependency on vascular nitric oxide. Arterioscler Thromb Vasc Biol 1996;16(1):44-50.

9. Kelm M. Nitric oxide metabolism and breakdown. Biochim Biophys Acta 1999;1411(2-3):273-89.

10. Oemar BS, Tschudi MR, Godoy N, Brovkovich V, Malinski T, Lüscher TF. Reduced endothelial nitric oxide synthase expression and production in human atherosclerosis. Circulation 1998;97(25):2494-8.

11. Sibal L, Agarwal SC, Home PD, Boger RH. The role of asymmetric dimethylarginine (ADMA) in endothelial dysfunction and cardiovascular disease. Curr Cardiol Rev 2010;6(2):82-90.

12. Sena CM, Pereira AM, Seiça R. Endothelial dysfunction: A major mediator of diabetic vascular disease. Biochim Biophys Acta 2013;1832(12):2216-31.

13. Bryan NS, Grisham MB. Methods to detect nitric oxide and its metabolites in biological samples. Free Radic Biol Med 2007;43(5):645-57.

14. Ranasinghe P, Cooray DN, Jayawardena R, Katulanda P. The influence of family history of hypertension on disease prevalence and associated metabolic risk factors among Sri Lankan adults. BMC Public Health 2015;15:576.

15. Ruilope LM. The kidney as a sensor of cardiovascular risk in essential hypertension. J Am Soc Nephrol 2002;13 Suppl 3:S165-8.

16. Ruilope LM, Lahera V, Rodicio JL, Romero JC. Participation of nitric oxide in the regulation of renal function: Possible role in the genesis of arterial hypertension. J Hypertens 1994;12(6):625-31.

17. Whelton PK, He J, Appel LJ, Cutler JA, Havas S, Kotchen TA, et al. Primary prevention of hypertension: Clinical and public health advisory from The National High Blood Pressure Education Program. JAMA 2002;288(15):1882-8

18. Eliot WJ, Bakris GL, Black HR. Hypertension: Epidemiology, pathophysiology, diagnosis, and treatment. In: Fuster V, Alexander RW, Hurst JW, O'Rourke RA, King SB III ${ }^{\text {rd }}$, Nash IS, et al., editors. In: Hurst's The Heart. 13 ${ }^{\text {th }}$ ed. USA: McGraw-Hill; 2011. p. 1549-80.

19. Tobian L. Dietary sodium chloride and potassium have effects on the pathophysiology of hypertension in humans and animals. Am J Clin Nutr 1997;65 2 Suppl:606S-11.

20. Levine BE, Weller JM, Remington RD. Serum sodium and potassium in essential hypertension. Circulation 1961;24:29-33.

21. Hvarfner A, Bergstrom R, Morlin C, Wide L, Ljunghall S. Relationships between calcium metabolic indices and blood pressure in patients with essential hypertension as compared with a healthy population. J Hypertens 1987;5(4):451-6.

22. Rees DD, Palmer RM, Moncada S. Role of endothelium-derived nitric oxide in the regulation of blood pressure. Proc Natl Acad Sci U S A 1989;86(9):3375-8.

23. Node K, Kitakaze M, Yoshikawa H, Kosaka H, Hori M. Reduced plasma concentrations of nitrogen oxide in individuals with essential hypertension. Hypertension 1997;30:405-8.

24. Arora S, Das N, Srivastava K. Nitric oxide and eNOS gene in essential hypertension. Int J Collab Res Intern Med Public Health 2009;1(2):56-71.

25. Chandra M, Maurya DR, Kumar S, Basara H, Ghatak A, Tekwani BL, et al. Reversible suppression of nitric oxide system in essential hypertension. Indian J Clin Biochem 2003;18(2):150-3. 